\title{
"Comment mon corps sait-il comment je vais?»
}

\author{
Christina Aus der Au
}

Prof. Dr théol., membre de la rédaction Ethique

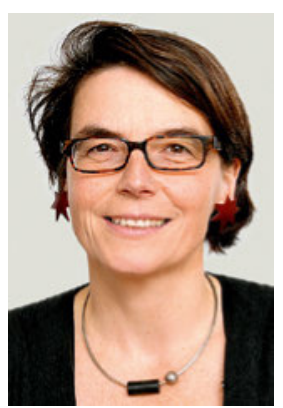

Ma fille de neuf ans est actuellement enthousiasmée par un poème de Robert Gernhardt. Il commence par: «Mein Körper sagt mir, ruh Dich aus!» (mon corps me dit, repose-toi!). Le moi du poète acquiesce sans broncher, mais écrit le poème en cachette. Bien sûr, il se fait vite réprimander par son corps, ce qui l'amène dans la dernière strophe à se poser la question: «wie weiss mein Körper, was ich tu?» (comment mon corps sait-il ce que je fais?)

C'est un poème drôle et à double sens. Rien d'étonnant à ce que ma fille saisisse toutes les occasions de le réciter avec plaisir. Quand je me vois prescrire quelques heures de physiothérapie, suite à d'horribles maux de dos, il finit par me trotter moi aussi dans la tête: comment mon corps sait-il ce que je fais? Là, en effet, l'aimable physiothérapeute m'appuie sur l'estomac et l'abdomen au point que je dois serrer les dents pour ne pas gémir. Et ma thérapeute commente sans hésitation: ...d'accord, l'estomac, le stress... rien d'étonnant!

Donc, le stress porte sur l'estomac. Certes, c'est passé dans le langage courant. Mais c'est autre chose de l'expérimenter aussi nettement sur son propre organisme. Ce qui m'effraie encore plus, c'est de constater la secrète satisfaction avec laquelle j'accueille cette information. Il est donc maintenant pour ainsi dire évident, voire prouvé, que je suis stressée. Ce stress peut être médicalement constaté sur mon corps, et n'est plus un simple ressenti subjectif. Il devient alors plus crédible pour les autres, mais aussi pour moi! Maintenant c'est avéré.

Je me suis mise à méditer sur la question. Pourquoi mon corps doit-il me prouver ce que je sais déjà? Pourquoi les états mentaux sont-ils apparemment plus reconnus quand ils se manifestent aussi de façon physique? D'un côté, derrière ces questions se cache bien entendu tout le débat sur la relation entre le corps et l'esprit: L'esprit et les sensations peuvent-ils être complètement représentés au niveau neuronal et physique? Quels sont les enjeux? D'un autre côté, cela révèle une conception du monde naturaliste, dont je n'étais absolument pas consciente: c'est finalement grâce au corps qu'on identifie ce qui se passe. Et pas seulement pour mes proches, à qui je pouvais désormais dire: regarde, ce n'est pas moi qui invente, c'est avéré; le médecin, la physiothérapeute a trouvé quelque chose! Manifestement, c'est important pour moi aussi. Il ne s'agit plus seulement de mon ressenti, c'est une réalité. J'en sais désormais plus sur moi.

Cela expliquerait-il tous les intéressants gadgets de type moniteurs d'activité physique, bracelets et programmes de jogging? Il ne s'agit peut-être pas tant de comparer avec les autres que d'obtenir une confirmation pour soi-même? Car nous doutons de nousmêmes, il nous faut le voir noir sur blanc: oui, tu es en forme, tu as déjà marché $7,5 \mathrm{~km}$ aujourd'hui, tu es en bonne santé. Aucun ressenti subjectif ne peut contrer ces informations! Je me sens également bien et détendue quand je mange une tablette de chocolat et que je m'allonge sur le canapé avec un livre passionnant. Mais justement, ça, ce n'est pas bien. Seuls les indicateurs et les chiffres peuvent me dire si c'est vraiment bien. Tout comme mon stress ne devient réel qu'à partir du moment où mon estomac réagit, et où il est diagnostiqué.

Je ne me fie pas à mon propre sentiment, j'ai besoin de faits. Des faits sur moi, que quelqu'un d'autre me fournit. Des faits me concernant, pour savoir comment je vais. Je ne suis pas directement moi, je ne suis que mon reflet dans mon corps. Même pas dans cette enveloppe corporelle, dans laquelle je m'incarne, que je sens, que je perçois et que j'expérimente. Les phénoménologues et les féministes ont mis en évidence il y a des années déjà que le moi avait une dimension physique. Il ne s'agit plus seulement de mon enveloppe corporelle, mais de mon corps, qui m'appartient et peut être examiné, pesé, mesuré par d'autres.

De nos jours, il faudrait même compléter le poème de R. Gernhardt. Il se termine par cette conclusion: «Die Frage scheint recht schlicht zu sein - doch ihre Schlichtheit ist nur Schein!» (la question semble très simple, elle est cependant loin de l'être!). Depuis, la question me taraude: comment mon corps sait-il ce que je fais? J'oserais proposer une autre strophe: «Si tu veux aller au fond des choses, ne laisse pas la question en plan. Car ce n'est qu'un commencement. Demande-toi plutôt: comment sait-il qui je suis?» 